\title{
A study of the $\mathrm{C}_{3} \mathrm{H}_{2}$ isomers and isotopologues: first interstellar detection of HDCCC $\star$
}

\author{
S. Spezzano ${ }^{1,3}$, H. Gupta ${ }^{2, \star \star}$, S. Brünken ${ }^{3}$, C. A. Gottlieb ${ }^{4}$, P. Caselli ${ }^{1}$, K. M. Menten ${ }^{5}$, H. S. P. Müller ${ }^{3}$, \\ L. Bizzocchi ${ }^{1}$, P. Schilke ${ }^{3}$, M. C. McCarthy ${ }^{4}$, and S. Schlemmer ${ }^{3}$ \\ 1 Max-Planck-Institut für extraterrestrische Physik, Giessenbachstr. 1, 85748 Garching, Germany \\ e-mail: spezzano@mpe.mpg.de \\ ${ }^{2}$ California Institute of Technology, 770 S. Wilson Ave., M/C 100-22, Pasadena, CA 91125, USA \\ 3 I. Physikalisches Institut, Universität zu Köln, Zülpicher Str. 77, 50937 Köln, Germany \\ ${ }^{4}$ Harvard-Smithsonian Center for Astrophysics, and School of Engineering \& Applied Sciences, \\ Harvard University, Cambridge, MA 02138, USA \\ 5 Max-Planck Institut für Radioastronomie, Auf dem Hügel 69, 53121 Bonn, Germany
}

Received 28 September 2015 / Accepted 12 November 2015

\section{ABSTRACT}

\begin{abstract}
The partially deuterated linear isomer HDCCC of the ubiquitous cyclic carbene $\left(c-\mathrm{C}_{3} \mathrm{H}_{2}\right)$ was observed in the starless cores TMC$1 \mathrm{C}$ and L1544 at $96.9 \mathrm{GHz}$, and a confirming line was observed in TMC-1 at $19.38 \mathrm{GHz}$. To aid the identification in these narrow line sources, four centimetre-wave rotational transitions (two in the previously reported $K_{\mathrm{a}}=0$ ladder and two new ones in the $K_{\mathrm{a}}=1$ ladder) and 23 transitions in the millimetre band between 96 and $272 \mathrm{GHz}$ were measured in high-resolution laboratory spectra. Ten spectroscopic constants in a standard asymmetric top Hamiltonian allow the main transitions of astronomical interest in the $K_{\mathrm{a}} \leq 3$ rotational ladders to be calculated to within $0.1 \mathrm{~km} \mathrm{~s}^{-1}$ in radial velocity up to $400 \mathrm{GHz}$. Conclusive identification of the two astronomical lines of HDCCC was provided by the $V_{\mathrm{LSR}}$, which is the same as for the normal isotopic species $\left(\mathrm{H}_{2} \mathrm{CCC}\right)$ in the three narrow line sources. In these sources, deuterium fractionation in singly substituted $\mathrm{H}_{2} \mathrm{CCC}\left(\mathrm{HDCCC} / \mathrm{H}_{2} \mathrm{CCC} \sim 4-19 \%\right)$ is comparable to that in $c-\mathrm{C}_{3} \mathrm{H}_{2}\left(c-\mathrm{C}_{3} \mathrm{H}_{2} / c-\mathrm{C}_{3} \mathrm{HD} \sim 5-17 \%\right)$ and similarly in doubly deuterated $c-\mathrm{C}_{3} \mathrm{H}_{2}\left(c-\mathrm{C}_{3} \mathrm{D}_{2} / c-\mathrm{C}_{3} \mathrm{HD} \sim 3-17 \%\right)$, implying that the efficiency of the deuteration processes in the $\mathrm{H}_{2} \mathrm{CCC}$ and $c-\mathrm{C}_{3} \mathrm{H}_{2}$ isomers are comparable in dark clouds.
\end{abstract}

Key words. astrochemistry - line: identification - ISM: molecules - ISM: clouds

\section{Introduction}

The study of deuterated molecules in the radio band yields constraints on the physical and chemical properties of the interstellar gas in the early stages of low-mass star formation (Caselli \& Ceccarelli 2012). Cyclopropenylidene $\left(c-\mathrm{C}_{3} \mathrm{H}_{2}\right)$ is one of the molecules frequently used in studies of deuterium fractionation in cold dark clouds, because lines of its rare isotopic species are relatively intense, the degree of fractionation is high, and $c-\mathrm{C}_{3} \mathrm{H}_{2}$ is believed to form solely by gas phase reactions (Gerin et al. 1987; Bell et al. 1988; Talbi \& Herbst 2001; Turner 2001; Liszt et al. 2012; Spezzano et al. 2013). During recent observations of the doubly deuterated species $c-\mathrm{C}_{3} \mathrm{D}_{2}$ towards the starless cores TMC-1C and L1544, Spezzano et al. (2013) observed an unidentified line in the millimetre band that was tentatively assigned to the singly deuterated form of propadienylidene $\left(\mathrm{H}_{2} \mathrm{CCC}\right)^{1}$, a highly polar metastable carbene $(\mu=4.17 \mathrm{D})$

\footnotetext{
* Based on observations carried out with the IRAM 30 m Telescope. IRAM is supported by INSU/CNRS (France), MPG (Germany) and IGN (Spain).

$\star \star$ Current address: Division of Astronomical Sciences National Science Foundation, 4201 Wilson Boulevard, Suite 1045, Arlington, VA 22230, USA.

1 Propadienylidene (Chemical Abstracts Services CAS \#: 60731-10-4) is usually designated in the spectroscopic and astronomical literature as $\mathrm{H}_{2}$ CCC (e.g., Vrtilek et al. 1990; Cernicharo et al. 1991) to distinguish it from its cyclic isomer $c-\mathrm{C}_{3} \mathrm{H}_{2}$, and because it has a same structure
}

about $14 \mathrm{kcal} \mathrm{mol}^{-1}(7045 \mathrm{~K})$ higher in energy than the more stable isomer $c-\mathrm{C}_{3} \mathrm{H}_{2}$ (Wu et al. 2010).

Propadienylidene $\left(\mathrm{H}_{2} \mathrm{CCC}\right)$ was detected in space by Cernicharo et al. (1991) and Kawaguchi et al. (1991) shortly after its millimetre-wave rotational spectrum was measured in the laboratory (Vrtilek et al. 1990). Initially, it was observed towards the cold dark cloud TMC-1 in the centimetre and millimetre bands, and the carbon-rich asymptotic giant branch (AGB) star IRC+10216 in the millimetre band. Here, we report the detection of a line of HDCCC in the prestellar cores TMC-1C and L1544 in the millimetre band at $96.9 \mathrm{GHz}$ and a confirming line in TMC-1 in the centimetre band at $19.38 \mathrm{GHz}$.

Although $\mathrm{H}_{2} \mathrm{CCC}$ was first observed nearly 25 years ago in the laboratory and the interstellar gas, the deuterated species had not been observed in any astronomical source and the rotational spectrum of the partially deuterated species HDCCC had not been measured in the millimetre band prior to this work, but the two lowest transitions in the centimetre band had been measured earlier (Kim \& Yamamoto 2005). In support of the astronomical identification of HDCCC and of future studies of the $\mathrm{C}_{3} \mathrm{H}_{2}$ isomeric system in the interstellar gas, the principal millimetrewave rotational transitions of astronomical interest have now been measured in high resolution laboratory spectra.

and symmetry as the well known molecules formaldehyde $\left(\mathrm{H}_{2} \mathrm{CO}\right)$ and ketene $\left(\mathrm{H}_{2} \mathrm{CCO}\right)$. Although propadienylidene is occasionally designated as $l-\mathrm{C}_{3} \mathrm{H}_{2}$, here we follow the example of spectroscopists and astronomers and refer to propadienylidene as $\mathrm{H}_{2} \mathrm{CCC}$. 


\section{Laboratory and astronomical observations}

\subsection{Laboratory}

Rotational lines of HDCCC were observed with the same $3 \mathrm{~m}$ long free-space double-pass absorption spectrometer used to measure the millimetre-wave spectrum of $c-\mathrm{C}_{3} \mathrm{D}_{2}$ (Spezzano et al. 2012). Guided by frequencies calculated with an effective rotational and centrifugal distortion constant derived from the two lowest transitions measured at centimetre wavelengths in a supersonic molecular beam (Kim \& Yamamoto 2005), lines of HDCCC were observed in the millimetre band. Following optimization of the normal isotopic species $\left(\mathrm{H}_{2} \mathrm{CCC}\right)$, the most intense lines of HDCCC were observed in a low pressure ( $\sim 18$ mTorr) DC discharge (140 mA) through a statistical mixture of deuterated acetylene (50\% HCCD, 25\% DCCD, and $25 \%$ $\mathrm{HCCH})$, carbon monoxide (CO), and argon (Ar) in a molar ratio of 10:5:1, with the walls of the discharge cell cooled to $150 \mathrm{~K}$. The acetylene sample was produced in real time by dropping an equal mixture of normal $\left(\mathrm{H}_{2} \mathrm{O}\right)$ and heavy water $\left(\mathrm{D}_{2} \mathrm{O}\right)$ on calcium carbide $\left(\mathrm{CaC}_{2}\right)$. Under these conditions, the signal-tonoise ratio $(\mathrm{S} / \mathrm{N})$ of lines of HDCCC near $160 \mathrm{GHz}$ was $\geq 10$ in 15 min of integration. In addition, the two lowest $K_{\mathrm{a}}=0$ lines in the centimetre band at 19 and $38 \mathrm{GHz}$ reported earlier by Kim $\&$ Yamamoto (2005) were remeasured with the FT microwave spectrometer described in Spezzano et al. (2012), and the two $K_{\mathrm{a}}=1$ transitions $\left(2_{1,2}-1_{1,1}\right.$ and $\left.2_{1,1}-1_{1,0}\right)$ were also measured.

In all, 27 rotational lines between 19 and $272 \mathrm{GHz}$ with $J \leq 14$ and $K_{\mathrm{a}} \leq 3$ (Table 1 ) are reproduced to an rms uncertainty $(28 \mathrm{kHz})$ that is comparable to the measurement uncertainties with ten spectroscopic constants in Watson's $S$ reduced Hamiltonian: three rotational constants, five fourth-order distortion constants ( $D_{K}$ was constrained to a theoretical value owing to the high correlation with $A$ ), and two sixth-order distortion constants (Table 2).

There is no evidence of deuterium hyperfine structure (hfs) when the fundamental transition of HDCCC is observed with high $\mathrm{S} / \mathrm{N}$ at a resolution of $1 \mathrm{kHz}$ in our molecular beam; therefore, no such structure should be present when this transition is observed in space. With these measurements, lines of HDCCC of principal astronomical interest in rotational ladders with $K_{\mathrm{a}} \leq 3$ can now be predicted to an accuracy of about $0.1 \mathrm{~km} \mathrm{~s}^{-1}$ for transitions up to $400 \mathrm{GHz}$, allowing for precise measurements of HDCCC in the interstellar gas.

The evidence that HDCCC is the carrier of the lines observed in our laboratory discharge is overwhelming. The close harmonicity of nine lines in the $K_{\mathrm{a}}=0$ rotational ladder with similar relative intensities confirms that there are no misassignments. The derived rotational constants are in excellent agreement with those predicted from a benchmark empirical equilibrium structure of $\mathrm{H}_{2} \mathrm{CCC}$ (Gauss \& Stanton 1999), combined with theoretical vibration-rotation interaction constants in Wu et al. (2010). Specifically, the measured constants $B$ and $C$ are within $0.03 \%$ of those estimated from the theoretical structure, and the fourthorder distortion constants are within a factor of two of the corresponding constants in $\mathrm{H}_{2} \mathrm{CCC}$ and within $20 \%$ of those that were calculated here at the B3LYP/cc-pVTZ level of theory and scaled by the ratio of the corresponding experimental (Gottlieb et al. 1993) and theoretical constants of the normal isotopic species $\mathrm{H}_{2}$ CCC. Additional evidence for this identification is provided by the relative intensities of lines of HDCCC that are the same to within $30 \%$ of those of $\mathrm{H}_{2} \mathrm{CCC}$ under the same conditions, after taking the statistical mixture of the deuterated acetylene precursor into account.
Table 1. Laboratory frequencies of HDCCC.

\begin{tabular}{cccr}
\hline \hline$J_{K_{\mathrm{a}}^{\prime} K_{\mathrm{c}}^{\prime}}^{\prime}-J_{K_{\mathrm{a}}^{\prime \prime}, K_{\mathrm{c}}^{\prime \prime}}^{\prime \prime}$ & $\begin{array}{c}\text { Frequency } \\
(\mathrm{MHz})\end{array}$ & $\begin{array}{c}\text { Unc. } \\
(\mathrm{kHz})\end{array}$ & $\begin{array}{r}\mathrm{O}^{-\mathrm{C}^{a}} \\
(\mathrm{kHz})\end{array}$ \\
\hline $1_{0,1}-0_{0,0}$ & 19384.5098 & 2 & 0.5 \\
$2_{1,2}-1_{1,1}$ & 38283.5891 & 2 & -0.6 \\
$2_{0,2}-1_{0,1}$ & 38768.0019 & 2 & 1.0 \\
$2_{1,1}-1_{1,0}$ & 39251.4274 & 2 & -0.1 \\
$5_{0,5}-4_{0,4}$ & 96902.196 & 20 & 0.6 \\
$6_{0,6}-5_{0,5}$ & 116271.438 & 20 & -6.5 \\
$7_{0,7}-6_{0,6}$ & 135634.586 & 20 & -8.5 \\
$8_{0,8}-7_{0,7}$ & 154990.661 & 20 & 26.6 \\
$9_{0,9}-8_{0,8}$ & 174338.544 & 20 & -13.6 \\
$10_{0,10}-9_{0,9}$ & 193677.324 & 20 & -40.1 \\
$10_{1,9}-9_{1,8}$ & 196204.056 & 24 & -15.1 \\
$12_{1,12}-11_{1,11}$ & 229614.027 & 23 & 55.9 \\
$12_{2,11}-11_{2,10}$ & 232512.813 & 20 & -6.9 \\
$12_{3,10}-11_{3,9}$ & 232544.540 & 21 & 57.5 \\
$12_{3,9}-11_{3,8}$ & 232546.625 & 21 & -34.7 \\
$12_{2,10}-11_{2,9}$ & 232775.855 & 20 & -6.1 \\
$12_{1,11}-11_{1,10}$ & 235415.394 & 19 & 22.5 \\
$13_{1,13}-12_{1,12}$ & 248731.752 & 19 & -24.1 \\
$13_{0,13}-12_{0,12}$ & 251629.269 & 20 & 32.3 \\
$13_{2,12}-12_{2,11}$ & 251875.722 & 20 & -15.2 \\
$13_{3,10}-12_{3,9}$ & 251927.366 & 33 & -42.7 \\
$13_{1,12}-12_{1,11}$ & 255015.024 & 20 & -28.7 \\
$14_{1,14}-13_{1,13}$ & 267845.608 & 37 & -56.7 \\
$14_{2,13}-13_{2,12}$ & 271235.509 & 12 & 8.1 \\
$14_{3,12}-13_{3,11}$ & 271303.986 & 41 & 41.2 \\
$14_{3,11}-13_{3,10}$ & 271308.664 & 28 & -29.1 \\
$14_{2,12}-13_{2,11}$ & 271653.245 & 20 & 13.6 \\
\hline & & & \\
\hline
\end{tabular}

Notes. ${ }^{(a)}$ Calculated with the spectroscopic constants in Table 2.

Table 2. Spectroscopic constants of HDCCC (in MHz).

\begin{tabular}{lcr}
\hline \hline Constant $^{a}$ & This work & \\
\hline$A$ & $199370 .(233)$ & 199755 \\
$B$ & $9934.22582(81)$ & 9936.8 \\
$C$ & $9450.29872(81)$ & 9452.8 \\
$D_{K}$ & $15.95^{d}$ & 15.95 \\
$D_{J K} \times 10^{3}$ & $353.89(50)$ & 413.19 \\
$D_{J} \times 10^{3}$ & $3.8082(33)$ & 3.79 \\
$d_{1} \times 10^{6}$ & $-256.62(164)$ & -235.43 \\
$d_{2} \times 10^{6}$ & $-91.00(250)$ & -107.81 \\
$H_{K J} \times 10^{6}$ & $-841 .(59)$ & \\
$H_{J K} \times 10^{6}$ & $8.53(122)$ & \\
\hline \multicolumn{3}{c}{}
\end{tabular}

Notes. ${ }^{(a)}$ Spectroscopic constants in Watson's $S$-reduced Hamiltonian in the $I^{r}$ representation. ${ }^{(b)}$ Numbers in parentheses are one standard deviation in units of the least significant digits. ${ }^{(c)}$ Rotational constants calculated with the empirical equilibrium structure of Gauss \& Stanton (1999) and the vibration-rotation interaction constants from $\mathrm{Wu}$ et al. (2010). The fourth-order centrifugal distortion constants were calculated at the B3LYP/cc-pVTZ level of theory and scaled by the ratio of the corresponding measured (Gottlieb et al. 1993) and theoretical constants of $\mathrm{H}_{2}$ CCC. ${ }^{(d)}$ Constrained to the theoretical value.

Predictions based on this work will be available online via the Cologne Database for Molecular Spectroscopy ${ }^{2}$ (Müller et al. 2005).

2 http://cdms.de 
Table 3. Observed line parameters of $\mathrm{H}_{2} \mathrm{CCC}$ in TMC-1C and L1544.

\begin{tabular}{|c|c|c|c|c|c|c|c|c|c|c|c|}
\hline $\begin{array}{l}\text { Transition } \\
J_{K_{\mathrm{a}} K_{\mathrm{c}}}^{\prime}-J_{K_{\mathrm{a}} K_{\mathrm{c}}}^{\prime \prime} \\
\end{array}$ & $\begin{array}{r}\text { Frequency } \\
(\mathrm{GHz})\end{array}$ & Ref. & $\begin{array}{r}E_{\text {up }} \\
\left(\mathrm{cm}^{-1}\right)\end{array}$ & $\begin{array}{c}T_{\mathrm{mb}} \\
(\mathrm{mK})\end{array}$ & $\begin{array}{c}\mathrm{rms} \\
(\mathrm{mK})\end{array}$ & $\begin{array}{c}W \\
\left(\mathrm{~K} \mathrm{~km} \mathrm{~s}^{-1}\right) \\
\end{array}$ & $\begin{array}{l}B_{\text {eff }} \\
(\%) \\
\end{array}$ & $\begin{array}{r}\theta_{\mathrm{MB}} \\
\left({ }^{\prime \prime}\right) \\
\end{array}$ & $\begin{array}{c}V_{\mathrm{LSR}^{a}} \\
\left(\mathrm{~km} \mathrm{~s}^{-1}\right)\end{array}$ & $\begin{array}{c}\Delta v^{a} \\
\left(\mathrm{~km} \mathrm{~s}^{-1}\right)\end{array}$ & $\begin{array}{c}N^{b} \\
\left(\times 10^{10} \mathrm{~cm}^{-2}\right) \\
\end{array}$ \\
\hline \multicolumn{12}{|c|}{ TMC- 1C $^{c}$} \\
\hline $4_{14}-3_{13}$ (ortho) & 82.395 & 1 & 6.18 & $70(9)$ & 7 & $0.024(2)$ & 81 & 30 & $5.98(1)$ & $0.32(3)$ & $27(1)$ \\
\hline $4_{04}-3_{03}$ (para) & 83.165 & 1 & 6.94 & $45(20)$ & 6 & $0.011(2)$ & 81 & 30 & $6.07(2)$ & $0.2(1)$ & $5.9(6)$ \\
\hline $5_{15}-4_{14}$ (ortho) & 102.992 & 1 & 9.62 & $57(10)$ & 7 & $0.012(2)$ & 80 & 25 & $5.97(1)$ & $0.18(3)$ & $25(2)$ \\
\hline \multirow{2}{*}{\multicolumn{12}{|c|}{$\mathbf{L 1 5 4 4}^{d}$}} \\
\hline & & & & & & & & & & & \\
\hline $5_{05}-4_{04}$ (para) & 103.953 & 1 & 10.40 & $53(12)$ & 10 & $0.024(4)$ & 80 & 25 & $7.18(3)$ & $0.42(7)$ & $\begin{array}{l}0(4) \\
30(3)\end{array}$ \\
\hline
\end{tabular}

Notes. ${ }^{(a)}$ Derived from a least-squares fit of Gaussian profiles to the spectra in Figs. 1 and 2. ${ }^{(b)}$ Calculated on the assumption that $T_{\text {ex }}$ is 4 K. ${ }^{(c)}$ Pointing position: $\alpha_{2000}=04^{\mathrm{h}} 41^{\mathrm{m}} 16^{\mathrm{s}} .1, \delta_{2000}=+25^{\circ} 49^{\prime} 43^{\prime \prime} .8{ }^{(d)}$ Pointing position: $\alpha_{2000}=05^{\mathrm{h}} 04^{\mathrm{m}} 17^{\mathrm{s}} .21, \delta_{2000}=+25^{\circ} 10^{\prime} 42^{\prime \prime} .8$.

References. (1) Vrtilek et al. (1990).

Table 4. Observed line parameters of HDCCC in TMC-1C and L1544.

\begin{tabular}{|c|c|c|c|c|c|c|c|c|c|c|c|}
\hline $\begin{array}{c}\text { Transition } \\
J_{K_{\mathrm{a}} K_{\mathrm{c}}}^{\prime}-J_{K_{\mathrm{a}} K_{\mathrm{c}}}^{\prime \prime}\end{array}$ & $\begin{array}{r}\text { Frequency } \\
(\mathrm{GHz})\end{array}$ & Ref. & $\begin{array}{r}E_{\text {up }} \\
\left(\mathrm{cm}^{-1}\right)\end{array}$ & $\begin{array}{c}T_{\mathrm{mb}} \\
(\mathrm{mK})\end{array}$ & $\begin{array}{l}\mathrm{rms} \\
(\mathrm{mK})\end{array}$ & $\begin{array}{c}W \\
\left(\mathrm{~K} \mathrm{~km} \mathrm{~s}^{-1}\right)\end{array}$ & $\begin{array}{l}B_{\text {eff }} \\
(\%)\end{array}$ & $\begin{array}{l}\theta_{\mathrm{MB}} \\
\left({ }^{\prime \prime}\right)\end{array}$ & $\begin{array}{c}V_{\mathrm{LSR}^{a}} \\
\left(\mathrm{~km} \mathrm{~s}^{-1}\right)\end{array}$ & $\begin{array}{c}\Delta v^{a} \\
\left(\mathrm{~km} \mathrm{~s}^{-1}\right)\end{array}$ & $\begin{array}{c}N^{b} \\
\left(\times 10^{9} \mathrm{~cm}^{-2}\right)\end{array}$ \\
\hline \multicolumn{12}{|c|}{ TMC- $1 C^{c}$} \\
\hline $5_{05}-4_{04}$ & 96.902 & 1 & 9.70 & $17(4)$ & 3 & $0.005(1)$ & 80 & 27 & $6.09(2)$ & $0.26(4)$ & $64(7)$ \\
\hline $7_{07}-6_{06}$ & 135.634 & 1 & 18.10 & $\leq 3$ & 3 & $\cdots$ & 76 & 18 & $\cdots$ & $\cdots$ & $\cdots$ \\
\hline \multicolumn{12}{|c|}{$\mathbf{L 1 5 4 4}^{d}$} \\
\hline $5_{05}-4_{04}$ & 96.902 & 1 & 9.70 & $12(4)$ & 3 & $0.005(1)$ & 80 & 27 & 7.31(5) & $0.41(1)$ & $71(7)$ \\
\hline
\end{tabular}

Notes. ${ }^{(a)}$ Derived from a least-squares fit of Gaussian profiles to the spectra in Figs. 1 and 2. ${ }^{(b)}$ Calculated on the assumption that $T_{\mathrm{ex}}$ is $4 \mathrm{~K}$. ${ }^{(c)}$ Pointing position: $\alpha_{2000}=04^{\mathrm{h}} 41^{\mathrm{m}} 16^{\mathrm{s}} .1, \delta_{2000}=+25^{\circ} 49^{\prime} 43^{\prime \prime} .8$. ${ }^{(d)}$ Pointing position: $\alpha_{2000}=05^{\mathrm{h}} 04^{\mathrm{m}} 17^{\mathrm{s}} \cdot 21, \delta_{2000}=+25^{\circ} 10^{\prime} 42^{\prime \prime} \cdot 8$.

References. (1) This work.

\subsection{Astronomical}

The millimetre-wave observations were done in several observing sessions between September 2012 and April 2014 with the IRAM $30 \mathrm{~m}$ telescope at Pico Veleta (Spain). The EMIR receivers in the E090 and E150 configuration were employed, and the observations were made by frequency switching with offsets of \pm 3.9 and $\pm 7.8 \mathrm{MHz}$ in the higher frequency band. All four EMIR sub-bands were connected to the FTS spectrometer, which was set to high resolution mode. The spectrum consisted of four $1.8 \mathrm{GHz}$ wide sub-bands with $50 \mathrm{kHz}$ channel spacing (corresponding to a velocity resolution of $0.15 \mathrm{~km} \mathrm{~s}^{-1}$ at $3 \mathrm{~mm}$ ) and a total spectral coverage of $7.2 \mathrm{GHz}$. The $J_{K_{2} K_{\mathrm{c}}}=$ $5_{05}-4_{04}$ transition of $\mathrm{H}_{2} \mathrm{CCC}$ in TMC-1C was observed with VESPA with a frequency resolution of $20 \mathrm{KHz}$. Telescope pointing (checked about every two hours) was accurate to $3^{\prime \prime}-4^{\prime \prime}$. The coordinates (see Tables 3 and 4) for TMC- $1 C^{3}$ are from Bell et al. (1988) and Gerin et al. (1987), and those of L1544 coincide with the peak of the $1.3 \mathrm{~mm}$ continuum dust emission from Ward-Thompson et al. (1999). The GILDAS ${ }^{4}$ software (Pety et al. 2005) was used for the data processing.

Observations of the fundamental rotational transition of HDCCC near $19.4 \mathrm{GHz}\left(J_{K_{\mathrm{a}} K_{\mathrm{c}}}=1_{01}-0_{00}\right)$ were made in 2007 October during a search for a rotational line of the $\mathrm{CCCN}^{-}$anion $^{5}$ in TMC-1 (Thaddeus et al. 2008) with the NRAO $100 \mathrm{~m}$

\footnotetext{
3 The source referred to here as TMC-1C, following the nomenclature from Bell et al. (1988), is listed as JCMTSF J044115.2+254932 in the SIMBAD database (http://cds.u-strasbg.fr).

4 http://www.iram.fr/IRAMFR/GILDAS

5 The $J=2-1$ transition of $\mathrm{CCCN}^{-}$is $22 \mathrm{MHz}$ higher in frequency than the fundamental transition of HDCCC.
}

Green Bank Telescope $(\mathrm{GBT})^{6}$. The corresponding transition of $\mathrm{H}_{2} \mathrm{CCC}$ near $20.8 \mathrm{GHz}$ was also observed during the same session, but only for a fairly short time ( $\sim 12 \mathrm{~min}$ vs. $12 \mathrm{~h}$ for HDCCC). The observing procedure was essentially the same as described in Brünken et al. (2007). The observations were done towards the Cyanopolyyne Peak of TMC-1 (see Table 5 for coordinates), and spectra were taken by position switching at a frequency resolution of $1.5 \mathrm{kHz}$ across the $50 \mathrm{MHz}$ band of the GBT spectrometer (other observing conditions were summarized in Thaddeus et al. 2008).

\subsubsection{HDCCC}

The $5_{0,5}-4_{0,4}$ transition of HDCCC at $96.9 \mathrm{GHz}$ was observed in TMC-1C and L1544 (Figs. 1 and 2). Because the $V_{\mathrm{LSR}}$ is in excellent agreement with that of other molecules in these two narrow line sources, these spectra provide strong evidence that HDCCC has been observed for the first time in the interstellar gas. The probability of a misidentification due to a line of another carrier coinciding to within twice the typical line width of about $200 \mathrm{kHz}$ is very small $\left(\sim 2 \times 10^{-3}\right)$, owing to the very low density of lines in these two sources of about 20 lines in each $1.8 \mathrm{GHz}$ wide sub-band. Additional evidence for an astronomical identification of HDCCC was sought by means of other transitions in the millimetre band; however, the rotational spectrum of HDCCC is not rich in lines. On the assumption that only levels in the $K_{\mathrm{a}}=0$ ladder are appreciably populated in these cold dense cores (those with $K_{\mathrm{a}} \neq 0$ are not metastable and are

6 The National Radio Astronomy Observatory is a facility of the National Science Foundation operated under cooperative agreement by Associated Universities, Inc. 

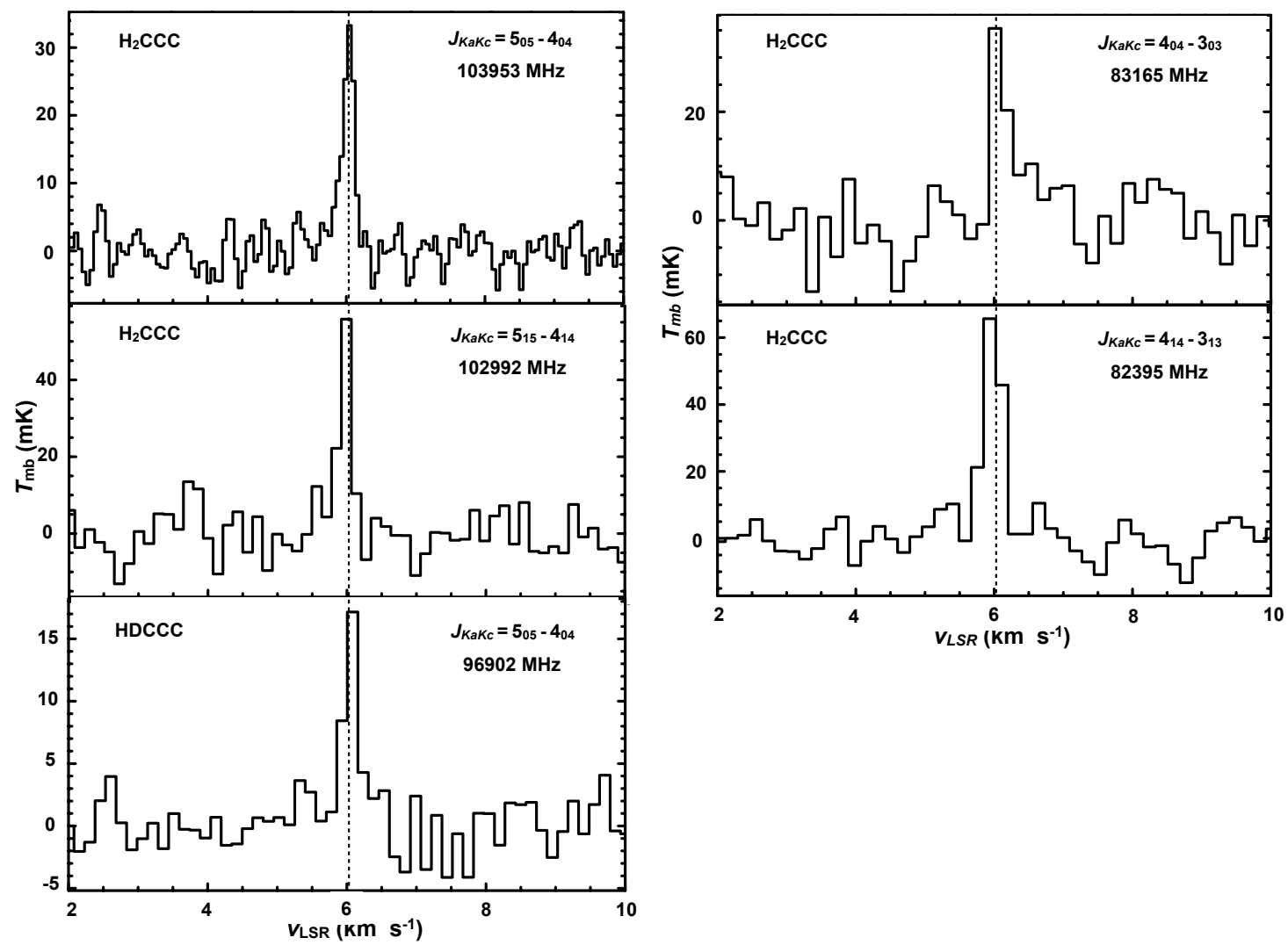

Fig. 1. Spectra of $\mathrm{H}_{2} \mathrm{CCC}$ and HDCCC observed towards TMC-1C with the IRAM $30 \mathrm{~m}$ telescope. The integration times for $\mathrm{H}_{2} \mathrm{CCC}$ were $3 \mathrm{~h}$ at 82 and $83 \mathrm{GHz}, 4 \mathrm{~h}$ at $102 \mathrm{GHz}$, and $23 \mathrm{~h}$ at $103 \mathrm{GHz}$. For HDCCC the integration time was $16 \mathrm{~h}$.

higher in energy by $\geq 12 \mathrm{~K}$ ), there are three transitions that are readily accessible with current ground-based telescopes and that might be detectable with deep integrations: the two lowest ones at 19 and $38 \mathrm{GHz}$ and one at $136 \mathrm{GHz}$.

Our initial attempt to detect a second line of HDCCC in the millimetre band was inconclusive. Although the transition at $135.6 \mathrm{GHz}$ was not detected in TMC-1C with the IRAM $30 \mathrm{~m}$ telescope, our upper limit of the main beam temperature at this frequency $(\leq 3 \mathrm{mK})$ is higher than predicted from the column density derived from the line at $96.9 \mathrm{GHz}$ on the assumption that the excitation temperature is $4 \mathrm{~K}$ (see Sect. 3). We then realized that the $1_{0,1}-0_{0,0}$ transition at $19 \mathrm{GHz}$ was covered in 2007 October in a deep search for the $\mathrm{CCCN}^{-}$anion in TMC-1 with the GBT (Thaddeus et al. 2008). Shown in Fig. 3 are the spectra with the fundamental transition of HDCCC and $\mathrm{H}_{2} \mathrm{CCC}$ in TMC- 1 at the precise $V_{\mathrm{LSR}}$ of $5.8 \pm 0.1 \mathrm{~km} \mathrm{~s}^{-1}$ in this much studied position in the Taurus molecular cloud, confirming our initial assignment of the line at $96.9 \mathrm{GHz}$ to the $5_{0,5}-4_{0,4}$ transition of HDCCC. As in the laboratory spectrum (Sect. 2.1), there is no evidence of deuterium hyperfine structure in the line in TMC-1 at $19 \mathrm{GHz}$.

\subsection{2. $\mathrm{H}_{2} \mathrm{CCC}$}

Simultaneous with the observations of HDCCC (Sect. 2.2.1), a para $\left(5_{0,5}-4_{0,4}\right)$ and an ortho $\left(5_{1,5}-4_{1,4}\right)$ transition of the main isotopic species $\mathrm{H}_{2} \mathrm{CCC}$ were observed in TMC-1C and L1544 in 2012 September; and two additional transitions $\left(4_{0,4}-3_{0,3}\right.$ and $\left.4_{1,4}-3_{1,3}\right)$ were observed in TMC-1C in 2014. The line parameters and derived column densities are reported in Table 3 , and the spectra are shown in Figs. 1 and 2.
Owing to the two equivalent off-axis hydrogen atoms, $\mathrm{H}_{2} \mathrm{CCC}$ has ortho and para symmetry states with a relative statistical weight (ortho/para) of 3:1, where rotational levels with odd $K_{\mathrm{a}}$ have ortho symmetry and those with even $K_{\mathrm{a}}$ have para symmetry. Monodeuterated HDCCC does not have ortho/para symmetry. It has been shown that the ortho/para ratio might depart from the statistical value, especially at the low temperatures that characterize cold dark cores, such as TMC-1C and L1544 ( $T=4-10 \mathrm{~K}$, Park et al. 2006). While analysing our data, we do not constrain the value of the ortho/para ratio, except in the case of TMC-1 where just one (para) line has been observed. In this case the ortho/para ratio was constrained to the statistical value (see Sect. 3).

\section{Analysis}

The column densities in Tables 3-5 were calculated with the following expression for optically thin transitions in rotational equilibrium at a temperature $T_{\text {ex }}$ (Goldsmith \& Langer 1999):

$\frac{N_{\mathrm{u}}}{g_{\mathrm{u}}}=\frac{J\left(T_{\mathrm{ex}}\right)}{J\left(T_{\mathrm{ex}}\right)-J\left(T_{\mathrm{bg}}\right)} \frac{3 k W}{8 \pi^{3} v S \mu^{2}}=\frac{N}{Z} \mathrm{e}^{\frac{E_{\mathrm{u}}}{k T_{\mathrm{ex}}}}$,

where $N_{\mathrm{u}}, g_{\mathrm{u}}$, and $E_{\mathrm{u}}$ are the column density, degeneracy, and energy of the upper state of the transition; $W$ is the integrated intensity; $v$ the frequency; $S$ the rotational line strength; $\mu$ the dipole moment; $Z$ the rotational partition function; and $J(T) \equiv \frac{h v}{k}\left(e^{\frac{h v}{k T}}-1\right)^{-1}$. The factor $J\left(T_{\mathrm{ex}}\right) /\left[J\left(T_{\mathrm{ex}}\right)-J\left(T_{\mathrm{bg}}\right)\right]$ accounts for the line absorption of the cosmic background radiation $\left(T_{\mathrm{bg}}=2.7 \mathrm{~K}\right)$, and is significantly larger than unity at the low excitation temperatures $\left(T_{\mathrm{ex}}<10 \mathrm{~K}\right)$ inferred for $\mathrm{H}_{2} \mathrm{CCC}$ and other polar molecules in cold dark clouds. The column densities were calculated assuming an excitation temperature of $4 \mathrm{~K}$, 
Table 5. Centimetre-wave lines of HDCCC and $\mathrm{H}_{2} \mathrm{CCC}$ in TMC-1.

\begin{tabular}{|c|c|c|c|c|c|c|c|c|c|c|c|}
\hline Molecule & $\begin{array}{c}\text { Transition } \\
J_{K_{\mathrm{a}} K_{\mathrm{c}}}^{\prime}-J_{K_{\mathrm{a}} K_{\mathrm{c}}}^{\prime \prime}\end{array}$ & $\begin{array}{c}\text { Frequency } \\
(\mathrm{GHz})\end{array}$ & Ref. & $\begin{array}{l}E_{\text {up }} \\
\left(\mathrm{cm}^{-1}\right)\end{array}$ & $\begin{array}{l}T_{\mathrm{A}}^{a} \\
(\mathrm{mK}) \\
\end{array}$ & $\begin{array}{c}W \\
\left(\mathrm{~K} \mathrm{~km} \mathrm{~s}^{-1}\right)\end{array}$ & $\begin{array}{l}\eta_{\mathrm{MB}} \\
(\%)\end{array}$ & $\begin{array}{l}\theta_{\mathrm{MB}} \\
\left({ }^{\prime \prime}\right) \\
\end{array}$ & $\begin{array}{c}V_{\mathrm{LSR}^{a}} \\
\left(\mathrm{~km} \mathrm{~s}^{-1}\right)\end{array}$ & $\begin{array}{l}\Delta v^{a} \\
\left(\mathrm{~km} \mathrm{~s}^{-1}\right)\end{array}$ & $\begin{array}{c}N^{b} \\
\left(10^{9} \mathrm{~cm}^{-2}\right)\end{array}$ \\
\hline & 1 & 4 & 1 & 0.647 & & 00 & 0 & 37 & & & 6) \\
\hline $\mathrm{H}_{2} \mathrm{CCC}$ (para) & $1_{01}-0_{00}$ & 20.792 & 2 & 0.694 & $158(19)$ & $0.054(18)$ & 0.867 & 36 & $5.71(7)$ & $0.28(4)$ & $769(231)^{c}$ \\
\hline
\end{tabular}

Notes. Pointing position for TMC-1: $\alpha_{2000}=04^{\mathrm{h}} 41^{\mathrm{m}} 42.49^{\mathrm{s}}, \delta_{2000}=+25^{\circ} 41^{\prime} 26.9^{\prime \prime}$. Estimated $1 \sigma$ uncertainties (in parentheses) are in units of the least significant digits. ${ }^{(a)}$ Derived from a least-squares fit of Gaussian profiles to the spectra in Fig. 3. ${ }^{(b)}$ Calculated on the assumption that $T_{\mathrm{ex}}=4 \mathrm{~K}$, the value derived for $\mathrm{H}_{2} \mathrm{CCC}$ in TMC-1 by Kawaguchi et al. (1991). ${ }^{(c)}$ For para $\mathrm{H}_{2}$ CCC. On the assumption that the ortho/para ratio is $3, N($ ortho + para $)=3076(923) \times 10^{9} \mathrm{~cm}^{-2}$.

References. (1) This work; (2) Vrtilek et al. (1990).

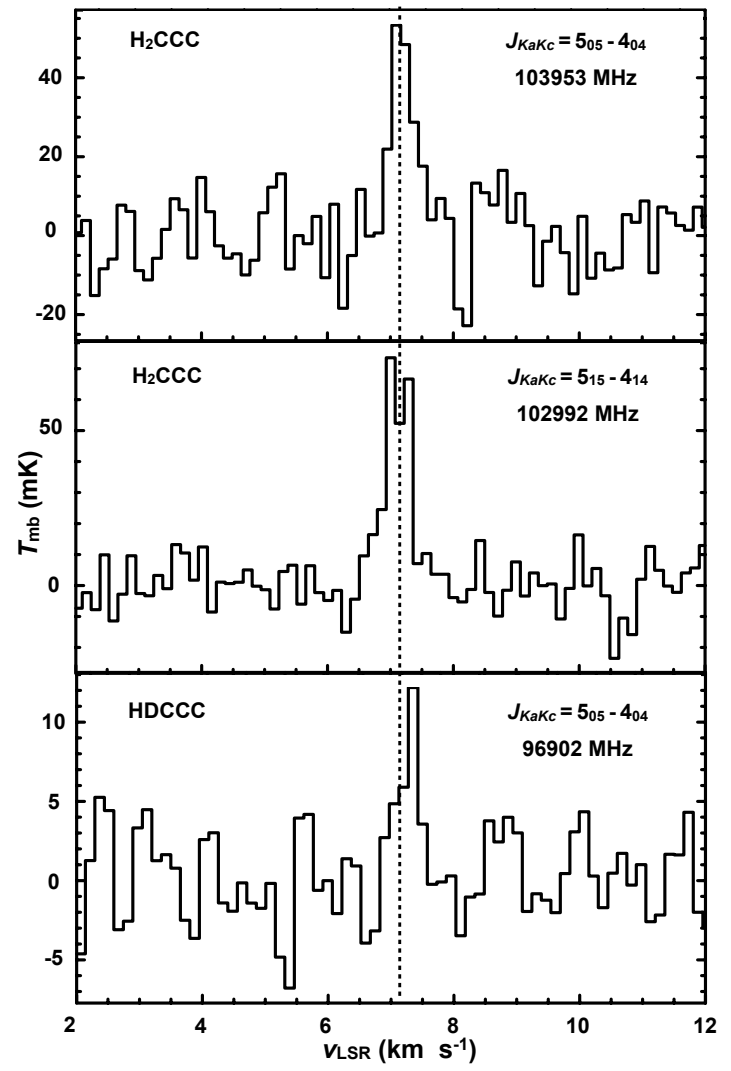

Fig. 2. Spectra of $\mathrm{H}_{2} \mathrm{CCC}$ and HDCCC observed towards L1544 with the IRAM $30 \mathrm{~m}$ telescope. The integration times were $4 \mathrm{~h}$ for $\mathrm{H}_{2} \mathrm{CCC}$ and $9.6 \mathrm{~h}$ for HDCCC.

by analogy with earlier work from Cernicharo et al. (1991) and Kawaguchi et al. (1991). On this assumption, from the column densities derived from the para and ortho lines of $\mathrm{H}_{2} \mathrm{CCC}$ in TMC-1C and L1544, we infer ortho/para ratio of $\sim 3$, which is consistent with the canonical ratio of 3 . There are three principal sources of uncertainty in our derived column densities of $\mathrm{H}_{2} \mathrm{CCC}$ and HDCCC: the excitation temperature, the ortho/para ratio in $\mathrm{H}_{2} \mathrm{CCC}$, and possible systematic uncertainties in the integrated areas of the observed line profiles. The results here allow us to derive the $\mathrm{D} / \mathrm{H}$ ratio in $\mathrm{H}_{2} \mathrm{CCC}$ in three sources for the first time. On the assumption that $T_{\mathrm{ex}}$ is $4 \mathrm{~K}$ in both $\mathrm{H}_{2} \mathrm{CCC}$ and $\mathrm{HDCCC}$, the $\mathrm{D} / \mathrm{H}$ ratio in $\mathrm{H}_{2} \mathrm{CCC}$ is $19 \pm 5 \%$ in TMC$1 \mathrm{C}$ and $6 \pm 1.3 \%$ in L1544 (Fig. 4). However, more observations are needed to better constrain the excitation temperature in both isotopic species and, in turn, the D/H ratio. Similarly, the centimetre-wave observation of the fundamental transition of $\mathrm{HDCCC}$ and para $\mathrm{H}_{2} \mathrm{CCC}$ allowed us to estimate an approximate

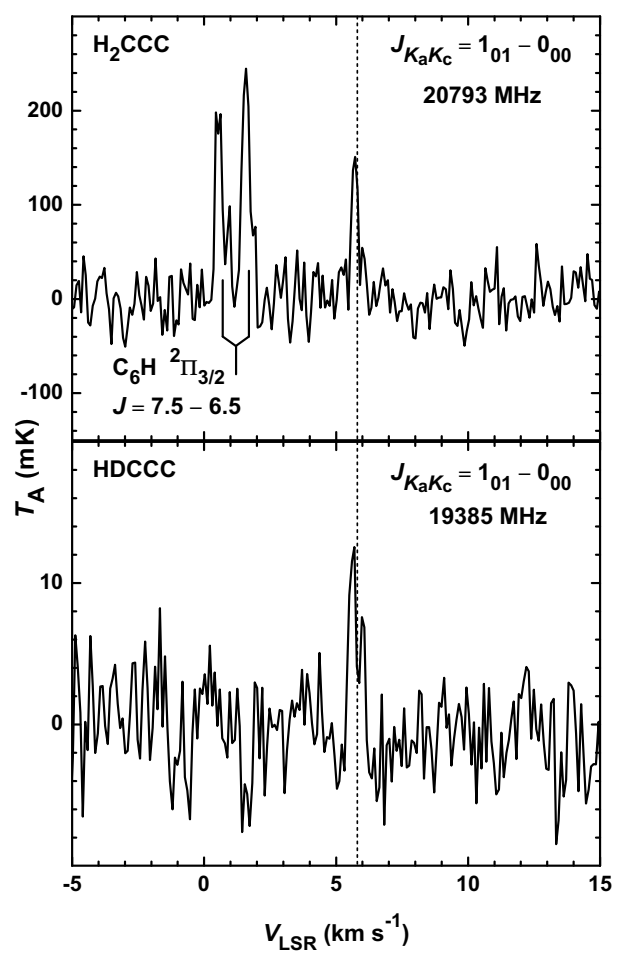

Fig. 3. Fundamental transitions of $\mathrm{HDCCC}$ and $\mathrm{H}_{2} \mathrm{CCC}$ in TMC-1. Also present in the upper panel is the hyperfine-split transition of $\mathrm{C}_{6} \mathrm{H}$ in the lower $\Lambda$ component $(e)$ at 20792.872 and $20792.945 \mathrm{MHz}$. Partially resolved kinematic structure is seen in the lines of $\mathrm{HDCCC}$ and $\mathrm{C}_{6} \mathrm{H}$, but not in $\mathrm{H}_{2} \mathrm{CCC}$ owing to the lower $\mathrm{S} / \mathrm{N}$. The dashed line at $+5.8 \mathrm{~km} \mathrm{~s}^{-1}$ indicates the systemic velocity of TMC-1. The integration time was approximately $11.5 \mathrm{~h}$ for the HDCCC and $12 \mathrm{~min}$ for the $\mathrm{H}_{2} \mathrm{CCC}$ spectrum. Both spectra were Hanning-smoothed to a frequency resolution of $6.1 \mathrm{kHz}$. A similar spectrum was observed by Cernicharo et al. (1987), see Fig. 2 lower left panel in their paper, and Fossé et al. (2001), see Fig. 1 upper panel. In the paper by Cernicharo et al. (1987), the line of $\mathrm{H}_{2} \mathrm{CCC}$ was reported as an unidentified feature because the laboratory spectrum of $\mathrm{H}_{2} \mathrm{CCC}$ was not known yet.

$\mathrm{D} / \mathrm{H}$ ratio in TMC-1. We find that the extent of the deuteration in TMC-1 ( $4 \pm 1.6 \%)$ is comparable to L1544, but is two-to-five times less than in TMC-1C.

\subsection{Excitation and abundance of $\mathrm{H}_{2} \mathrm{CCC}$ and HDCCC}

To determine whether LTE is a good approximation for estimating the rotational excitation temperature $\left(T_{\mathrm{ex}}\right)$ and column density $(N)$ of $\mathrm{H}_{2} \mathrm{CCC}$ and HDCCC (Sect. 3), $T_{\text {ex }}$ and $N$ were compared with the corresponding properties of $\mathrm{H}_{2} \mathrm{CCC}$ 


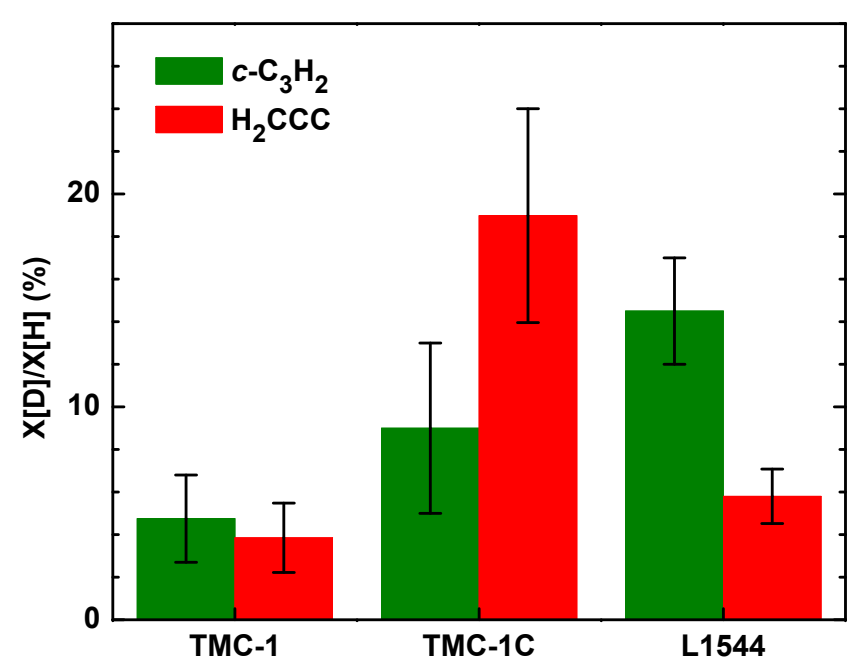

Fig. 4. D/H isotopic ratio in the carbene isomers $\mathrm{H}_{2} \mathrm{CCC}$ and $c-\mathrm{C}_{3} \mathrm{H}_{2}$ in three dense cores in the Taurus molecular cloud: TMC-1, TMC-1C, and L1544. For $c-\mathrm{C}_{3} \mathrm{H}_{2}$, the heights of the bars indicate the average value, and the error bars the range of values inferred in previous studies of TMC-1 (Turner 2001) and of TMC-1C and L1544 (Spezzano et al. 2013).

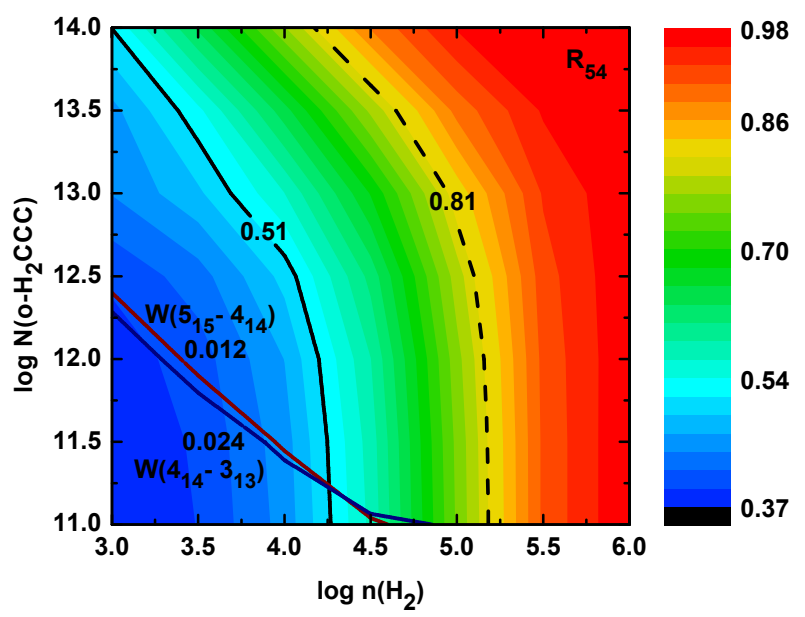

Fig. 5. Integrated area (W) for the $4_{1,4}-3_{1,3}$ transition (blue contour) and $5_{1,5}-4_{1,4}$ transition (red contour) of $\mathrm{H}_{2} \mathrm{CCC}$, and the ratio of the integrated areas $\mathrm{R}_{54}$ (solid black contour) versus the total column density of ortho $\mathrm{H}_{2} \mathrm{CCC}$ and the $\mathrm{H}_{2}$ density.

obtained from statistical equilibrium calculations with RADEX (van der Tak et al. 2007). The calculations were done for a uniform spherical geometry for TMC-1C, a line width of $0.3 \mathrm{~km} \mathrm{~s}^{-1}$ (FWHM), a kinetic temperature of $10 \mathrm{~K}$, and a radiation temperature of 2.73 K. Following Cernicharo et al. (1999), we used collisional de-excitation rates that are two times higher than those for ortho- $\mathrm{H}_{2} \mathrm{CO}$ with para $\mathrm{H}_{2}$ as provided in the LAMDA database (Schöier et al. 2005; Wiesenfeld \& Faure 2013). Only the lowest 18 rotational levels in the $K_{\mathrm{a}}=1$ ladder of $\mathrm{H}_{2} \mathrm{CCC}$ were included, because the cross-ladder collisional rates $(\Delta K=$ 2 ) are nearly an order of magnitude lower. Similarly, collisions with ortho- $\mathrm{H}_{2}$ were neglected because the ortho/para ratio for $\mathrm{H}_{2}$ is negligible at $10 \mathrm{~K}$ (cf., Troscompt et al. 2009).

Summarized in Figs. 5-7 are the results of the statistical equilibrium calculations. It is evident that the integrated areas (W) of the two ortho transitions of $\mathrm{H}_{2} \mathrm{CCC}$ and the ratio of the two imply that $\log n\left(\mathrm{H}_{2}\right) \sim 4.25$ and $\log N \sim 11.25$ (i.e.,

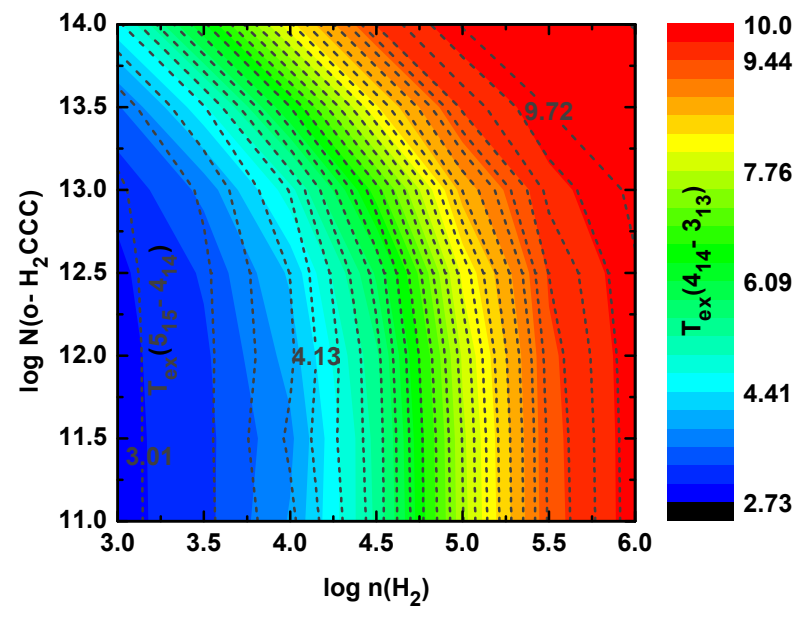

Fig. 6. Dependence of the excitation temperature $\left(T_{\mathrm{ex}}\right)$ of the $4_{1,4}-3_{1,3}$ and $5_{1,5}-4_{1,4}$ transitions of ortho $\mathrm{H}_{2} \mathrm{CCC}$ on the column density and the $\mathrm{H}_{2}$ density, on the assumption that the kinetic temperature is $10 \mathrm{~K}$. The colour scale applies to the $4_{1,4}-3_{1,3}$ transition and the dashed contours to the $5_{1,5}-4_{1,4}$ transition.
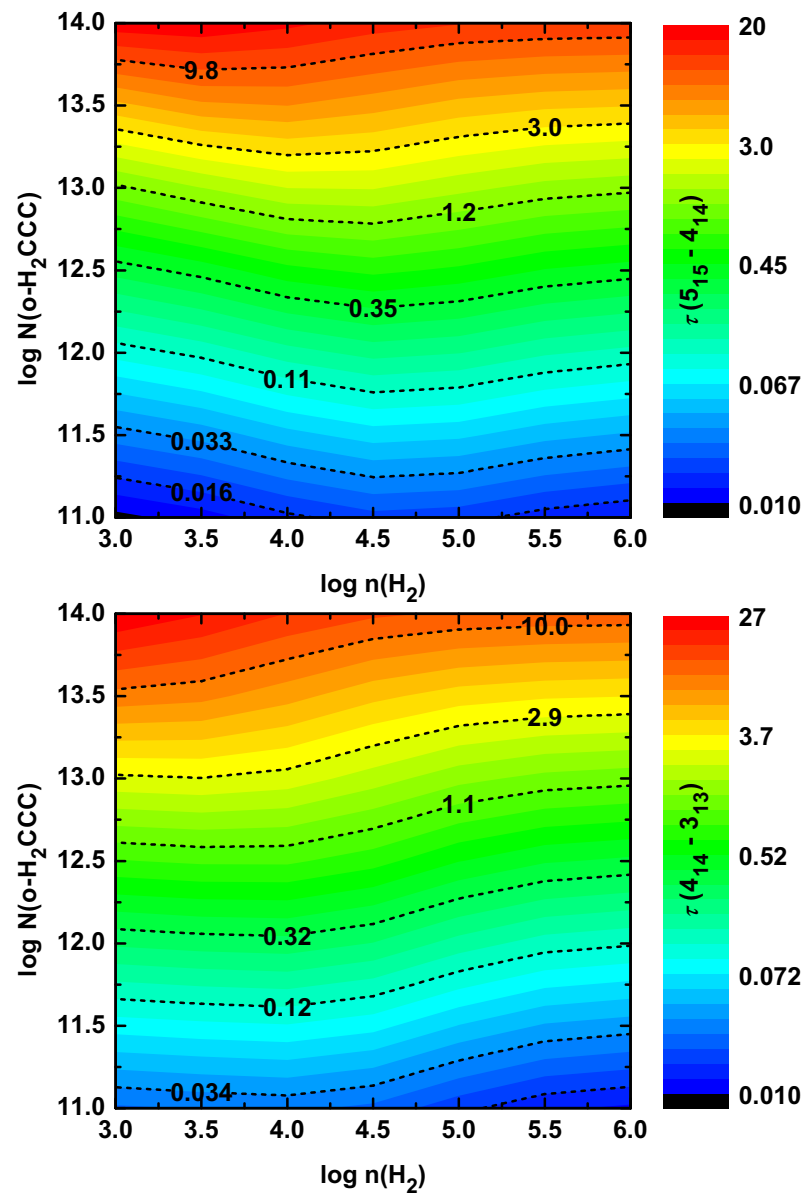

Fig. 7. Dependence of the optical depths $(\tau)$ of the $4_{1,4}-3_{1,3}$ and $5_{1,5}-4_{1,4}$ transitions of ortho $\mathrm{H}_{2} \mathrm{CCC}$ on the column density and the $\mathrm{H}_{2}$ density.

$n\left(\mathrm{H}_{2}\right)=2 \times 10^{4} \mathrm{~cm}^{-3}$ and $N=2 \times 10^{11} \mathrm{~cm}^{-2}$; Fig. 5). Under the same conditions we estimate that $T_{\mathrm{ex}} \sim 4 \mathrm{~K}$ (Fig. 6), and $\mathrm{H}_{2} \mathrm{CCC}$ is optically thin in both transitions (i.e., $\tau \leq 0.05$ in $4_{1,4}-3_{1,3}$ and $5_{1,5}-4_{1,4}$; Fig. 7). As a result, we find that the rotational 
Table 6. Column density and excitation temperature of ortho $\mathrm{H}_{2} \mathrm{CCC}$ in TMC-1C.

\begin{tabular}{lcc}
\hline \hline Property & LTE & RADEX \\
\hline$N\left(\mathrm{~cm}^{-2}\right)$ & $2.6 \times 10^{11 a}$ & $1.8 \times 10^{11}$ \\
$T_{\text {ex }}(\mathrm{K})$ & $4^{b}$ & $4.6^{c}$ \\
$T_{\text {kinetic }}(\mathrm{K})$ & $\cdots$ & 10.0 \\
\hline
\end{tabular}

Notes. ${ }^{(a)}$ Average value of the column densities reported in Table 3 for ortho- $\mathrm{H}_{2} \mathrm{CCC}$ in TMC-1C. ${ }^{(b)} T_{\mathrm{ex}}$ assumed by analogy with Cernicharo et al. (1991) and Kawaguchi et al. (1991). ${ }^{(c)}$ Approximate mean of $4.4 \mathrm{~K}$ for the $5_{1,5}-4_{1,4}$ transition and $4.8 \mathrm{~K}$ for the $4_{1,4}-3_{1,3}$ transition at $\log n=4.25$ and $\log N=11.25$.

temperature derived for $\mathrm{H}_{2} \mathrm{CCC}$ in TMC- 1 by Cernicharo et al. (1991) and Kawaguchi et al. (1991) is valid for TMC-1C, hence also a valid assumption for L1544. We also find that the column density derived for ortho $\mathrm{H}_{2} \mathrm{CCC}$ on the assumption of LTE is essentially the same as derived with RADEX (see Table 6).

\section{Discussion}

The present work is a preliminary study of different isomers and isotopologues of the $\mathrm{C}_{3} \mathrm{H}_{2}$ system. Isomers and isotopologues are precious tools for astrochemists because they convey useful information for disentangling different chemical routes that might correspond to different physical conditions. In particular, the astrophysically relevant properties of the $\mathrm{C}_{3} \mathrm{H}_{2}$ system studied in this paper are the $\mathrm{D} / \mathrm{H}$ abundance ratio in each isomer and the cyclic-to-linear abundance ratio.

The cyclic-to-linear isomeric ratio of $\mathrm{C}_{3} \mathrm{H}_{2}$ appears to depend on the region where the isomers are observed, meaning that the $c-\mathrm{C}_{3} \mathrm{H}_{2} / \mathrm{H}_{2} \mathrm{CCC}$ ratio increases with decreasing electron abundance (Fossé et al. 2001). A summary of the $c-\mathrm{C}_{3} \mathrm{H}_{2} / \mathrm{H}_{2} \mathrm{CCC}$ ratio in different environments is reported in Table 7. In dense molecular clouds, the ratio is between 20 and 40 (Kawaguchi et al. 1991; Cernicharo et al. 1991; Fossé et al. 2001), while in diffuse clouds it is lower by one order of magnitude (Cernicharo et al. 1999). In the Horsehead nebula PDR, the $c-\mathrm{C}_{3} \mathrm{H}_{2} / \mathrm{H}_{2} \mathrm{CCC}$ ratio has a value of three to five in the diffuse gas, and it increases by a factor of 4 when penetrating in the denser region of the cloud (Teyssier et al. 2005). Towards the Orion Bar a $c-\mathrm{C}_{3} \mathrm{H}_{2} / \mathrm{H}_{2} \mathrm{CCC}$ ratio of 34 has been observed very recently (Cuadrado et al. 2015). Perhaps alternative formation/destruction routes occur towards the Orion Bar, which is a very extreme environment ( $>300$ times the far-UV radiation flux with respect to the Horsehead nebula), which might allow endothermic reactions and reactions with a high energy barrier to become efficient. The $c-\mathrm{C}_{3} \mathrm{H}_{2} / \mathrm{H}_{2} \mathrm{CCC}$ ratio in TMC- $1 \mathrm{C}$ is about two times higher than in TMC-1, along the filament in TMC-1 (see Fig. 3 in Fossé et al. (2001), and in L1544. The causes for this behaviour might be a systematic error in the $\mathrm{H}_{2} \mathrm{CCC}$ column density (see Sect. 3), the overall difficulty in deriving accurate column densities of $c-\mathrm{C}_{3} \mathrm{H}_{2}$, or different physical conditions in TMC-1C with respect to TMC-1 and L1544.

The variation in the cyclic-to-linear ratio in different environments is related to distinct destruction and possibly formation pathways for the two isomers. These pathways still need to be fully understood. Talbi et al. (2009) present the results of calculations on the dissociative recombination of cyclic and linear $\mathrm{C}_{3} \mathrm{H}_{3}^{+}$with electrons. It is shown that the formation of $c-\mathrm{C}_{3} \mathrm{H}_{2}$ from $c-\mathrm{C}_{3} \mathrm{H}_{3}^{+}$is more efficient than the formation of $\mathrm{H}_{2} \mathrm{CCC}$ from $l-\mathrm{C}_{3} \mathrm{H}_{3}^{+}$. A similar result was obtained by Adams \& Babcock (2005), who in fact observed in an afterglow experiment that the cyclic $\mathrm{C}_{3} \mathrm{H}_{3}^{+}$recombines with electrons faster than the linear isomer. Interestingly, Chabot et al. (2013) show that with their new semiempirical model for calculating branching ratios while $c-\mathrm{C}_{3} \mathrm{H}$ is the main product of the dissociative recombination of $c-\mathrm{C}_{3} \mathrm{H}_{2}^{+}$with electrons, $l-\mathrm{C}_{3} \mathrm{H}$ is not the main product of the recombination of $l-\mathrm{C}_{3} \mathrm{H}_{2}^{+}$with electrons. Unfortunately, the branching ratios of the dissociative recombination of linear and cyclic $\mathrm{C}_{3} \mathrm{H}_{3}^{+}$are not provided in Chabot et al. (2013).

The formation of $c-\mathrm{C}_{3} \mathrm{HD}$ and $c-\mathrm{C}_{3} \mathrm{D}_{2}$ in dense cores has been studied for a long time (Gerin et al. 1987; Bell et al. 1988; Spezzano et al. 2013), and it is believed to occur through subsequent deuteration of $c-\mathrm{C}_{3} \mathrm{H}_{2}$ via reactions with $\mathrm{H}_{2} \mathrm{D}^{+}, \mathrm{D}_{2} \mathrm{H}^{+}$, and $\mathrm{D}_{3}{ }^{+}$followed by the dissociative recombination of the ionic intermediate with electrons (see Fig. 3 in Spezzano et al. 2013). The intermediates of this reaction scheme are $\mathrm{C}_{3} \mathrm{H}_{3}^{+}, \mathrm{C}_{3} \mathrm{H}_{2} \mathrm{D}^{+}$, $\mathrm{C}_{3} \mathrm{HD}_{2}^{+}$, and $\mathrm{C}_{3} \mathrm{D}_{3}^{+}$. When shown schematically, singly deuterated carbenes are produced by the formal reactions

$$
\begin{aligned}
& \mathrm{RH}_{2}+\mathrm{H}_{2} \mathrm{D}^{+} \rightarrow \mathrm{RH}_{2} \mathrm{D}^{+}+\mathrm{H}_{2} \\
& \mathrm{RH}_{2} \mathrm{D}^{+}+\mathrm{e}^{-} \rightarrow \mathrm{RHD}+\mathrm{H}
\end{aligned}
$$

where $\mathrm{RH}_{2} \equiv c-\mathrm{C}_{3} \mathrm{H}_{2}$ (or $\mathrm{H}_{2} \mathrm{CCC}$ ), and the doubly deuterated carbenes by the reactions

$$
\begin{aligned}
& \mathrm{RHD}+\mathrm{H}_{2} \mathrm{D}^{+} \rightarrow \mathrm{RHD}_{2}^{+}+\mathrm{H}_{2} \\
& \mathrm{RHD}_{2}^{+}+\mathrm{e}^{-} \rightarrow \mathrm{RD}_{2}+\mathrm{H} .
\end{aligned}
$$

For simplicity only the reactions with $\mathrm{H}_{2} \mathrm{D}^{+}$are shown, but the same set of reactions will proceed with $\mathrm{D}_{2} \mathrm{H}^{+}$and $\mathrm{D}_{3}^{+}$. Table 7 and Fig. 4 report the $\mathrm{D} / \mathrm{H}$ abundance ratios in both the cyclic and linear isomers of $\mathrm{C}_{3} \mathrm{H}_{2}$ in TMC-1C, L1544, and TMC-1. The $\mathrm{D} / \mathrm{H}$ abundance ratio in both the cyclic and linear form of $\mathrm{C}_{3} \mathrm{H}_{2}$ are similar in all our observations, suggesting that the deuteration of the linear isomer might follow the same reaction scheme as the cyclic, with the difference that the deuteration of the linear isomer will not proceed as straightforwardly as the cyclic. In contrast to the cyclic, the linear deuterated intermediate ion $\left(\mathrm{H}_{2} \mathrm{CCCD}^{+}\right)$will have to undergo atom exchange or structural rearrangement while recombining with electrons, otherwise it will react back to $\mathrm{H}_{2} \mathrm{CCC}$. More experimental and theoretical studies are required to understand the detailed mechanism of deuteration of $\mathrm{H}_{2} \mathrm{CCC}$. TMC-1C shows an enhanced deuteration in the linear isomer compared to the cyclic. Given the difficulty in deriving accurate column densities for $c-\mathrm{C}_{3} \mathrm{H}_{2}$, and the possibility of having a systematic error in the column density derived for $\mathrm{H}_{2} \mathrm{CCC}$ in TMC-1C, the authors do not feel the necessity to put too much emphasis on this result.

In dense prestellar and protostellar dark cloud cores, the $c-\mathrm{C}_{3} \mathrm{HD} / c-\mathrm{C}_{3} \mathrm{H}_{2}$ and $c-\mathrm{C}_{3} \mathrm{D}_{2} / c-\mathrm{C}_{3} \mathrm{HD}$ ratios are very similar to those in dark clouds (Table 7), in spite of the different mechanisms thought to govern the abundances of unsaturated carbon chains and carbenes in these regions. In addition to the ionmolecule processes that produce carbon chains and carbenes in prestellar cores and cold dark clouds, sublimation of methane from grain mantles warmed up by the faint protostar is hypothesized to yield elevated abundances of carbon chains and carbenes in low-mass protostellar cores (see Cordiner et al. 2012, for a summary of the proposed mechanisms). Similar D/H ratios in prestellar and protostellar cores indicate that once the nondeuterated carbene is formed, the singly and doubly deuterated carbene are produced by reactions (2) to (5), notwithstanding the formation mechanism. 
Table 7. Isomeric and $\mathrm{D} / \mathrm{H}$ ratios of $\mathrm{H}_{2} \mathrm{CCC}$ and $c-\mathrm{C}_{3} \mathrm{H}_{2}$ in six Galactic regions.

\begin{tabular}{|c|c|c|c|c|c|c|c|c|}
\hline \multirow[t]{2}{*}{ Property } & \multicolumn{2}{|c|}{ Prestellar core } & \multicolumn{2}{|c|}{ Protostellar core } & \multirow{2}{*}{$\begin{array}{c}\text { Dark cloud } \\
\text { TMC-1 }\end{array}$} & \multirow{2}{*}{$\begin{array}{c}\text { Translucent }^{a} \\
\text { (Average) }\end{array}$} & \multirow{2}{*}{$\begin{array}{l}\text { Diffuse }^{b} \\
\text { (Mean) }\end{array}$} & \multirow[t]{2}{*}{$\mathrm{PDR}^{c}$} \\
\hline & TMC-1C & L1544 & ${\mathrm{L} 1527^{d}}$ & Cha-MMS1 ${ }^{e}$ & & & & \\
\hline$N\left(c-\mathrm{C}_{3} \mathrm{H}_{2}\right) \mathrm{cm}^{-2}$ & $2.2^{h} \times 10^{13}$ & $3.7^{h} \times 10^{13}$ & $1.3 \times 10^{13}$ & $2.7 \times 10^{13}$ & $0.58^{\mathrm{g}} \times 10^{14}$ & $2.4 \times 10^{13}$ & $3.3 \times 10^{12}$ & $9.3 \times 10^{12}$ \\
\hline$N\left(\mathrm{H}_{2} \mathrm{CCC}\right) \mathrm{cm}^{-2}$ & $3.3 \times 10^{11}$ & $1.1 \times 10^{12}$ & $1.1 \times 10^{12}$ & $\cdots$ & $\left(2.1^{\mathrm{g}}-\mathbf{3 . 1}\right) \times 10^{12}$ & $2.5 \times 10^{12}$ & $1.9 \times 10^{11}$ & $2.7 \times 10^{12}$ \\
\hline$c-\mathrm{C}_{3} \mathrm{H}_{2} / \mathrm{H}_{2} \mathrm{CCC}$ & $67 \pm 7^{f}$ & $32 \pm 4$ & 12 & . & $28 \pm 6^{g}$ & 9 & 17 & 3 \\
\hline$c-\mathrm{C}_{3} \mathrm{HD} / c-\mathrm{C}_{3} \mathrm{H}_{2}$ & $(5-13) \%^{h} 10 \%^{i}$ & $(12-17) \%^{h} 15 \%{ }^{i, j}$ & $(7-18) \%$ & $(5-34) \%$ & $8 \%^{i} 5 \%^{k}$ & $\cdots$ & $\ldots$ & $\ldots$ \\
\hline$c-\mathrm{C}_{3} \mathrm{D}_{2} / c-\mathrm{C}_{3} \mathrm{HD}$ & $(3-15) \%^{h}$ & $(7-17) \%^{h}$ & $2.6 \%^{l}$ & $\ldots$ & $\ldots$ & $\ldots$ & $\ldots$ & $\ldots$ \\
\hline $\mathrm{HDCCC} / \mathrm{H}_{2} \mathrm{CCC}$ & $19 \pm 5 \%$ & $6 \pm 1.3 \%$ & $\ldots$ & $\ldots$ & $4 \pm 1.6 \%$ & $\ldots$ & $\ldots$ & $\ldots$ \\
\hline
\end{tabular}

Notes. Quantities in boldface are from this work.

References. ${ }^{(a)}$ From Table 20 in Turner (2000) and references therein. ${ }^{(b)}$ Liszt et al. (2012). ${ }^{(c)}$ Pety et al. (2012). ${ }^{(d)}$ From Table 1 in Sakai \& Yamamoto (2013) and references therein. ${ }^{(e)}$ Cordiner et al. (2012). ${ }^{(f)}$ See Sects. 3.1 and 4. ${ }^{(g)}$ Fossé et al. (2001). ${ }^{(h)}$ Spezzano et al. (2013). ${ }^{(i)}$ Bell et al. (1988). ${ }^{(j)}$ Gerin et al. (1987). ${ }^{(k)}$ See Table 12 in Turner (2001). ${ }^{(l)}$ Tokudome et al. (2013).

A plausible explanation for the similar $\mathrm{D} / \mathrm{H}$ ratios of $c-\mathrm{C}_{3} \mathrm{H}_{2}$ in the two types of dark cloud cores is as follows. Owing to freeze-out in the inner regions of prestellar cores - by analogy with the well-known case of $\mathrm{HCO}^{+}$and $\mathrm{DCO}^{+}$, which are heavily depleted in the cold inner regions of prestellar cores carbenes reside primarily in the warmer outer regions (Caselli 2002). As a result, if the abundance of $\mathrm{H}_{2} \mathrm{D}^{+}$and the electron fraction in the outer regions of prestellar cores are similar to those in protostellar cores ${ }^{7}$, according to reactions (2) to (5), similar $c-\mathrm{C}_{3} \mathrm{HD} / c-\mathrm{C}_{3} \mathrm{H}_{2}$ and $c-\mathrm{C}_{3} \mathrm{D}_{2} / c-\mathrm{C}_{3} \mathrm{HD}$ ratios are expected. There are no observations of HDCCC in protostellar cores, but the next larger cumulene carbene HDCCCC has been detected in L1527 at $\sim 3-4 \%$ that of $\mathrm{H}_{2}$ CCCC (Sakai et al. 2009b). Therefore, it would not be surprising if the $\mathrm{HDCCC} / \mathrm{H}_{2} \mathrm{CCC}$ ratio in L1527 and other protostellar cores is similar to ratios in dense prestellar cores and dark clouds.

To gain a more conclusive understanding of the chemistry of the $\mathrm{C}_{3} \mathrm{H}_{2}$ system, the HDCCC/ $\mathrm{H}_{2} \mathrm{CCC}$ and the $c-\mathrm{C}_{3} \mathrm{HD} / c-\mathrm{C}_{3} \mathrm{D}_{2}$ ratios should be systematically studied in a larger sample of dense cores. For example, Emprechtinger et al. (2009) have investigated the use of the $\mathrm{N}_{2} \mathrm{D}^{+} / \mathrm{N}_{2} \mathrm{H}^{+}$ratio as an evolutionary tracer of Class 0 protostars. A comparison with the results obtained by Emprechtinger et al. (2009) would clarify whether the $\mathrm{C}_{3} \mathrm{H}_{2}$ system fails to be an evolutionary tracer, because carbenes are heavily depleted in the inner core of the cloud. Future observations with interferometers, NOEMA, and ALMA will shine some light on how the deuteration of different tracers changes with radial distance from the prestellar and protostellar core. More precise inferences derived from the observed $\mathrm{D} / \mathrm{H}$ ratios in $c-\mathrm{C}_{3} \mathrm{H}_{2}$ and $\mathrm{H}_{2} \mathrm{CCC}$ will also require further laboratory kinetic measurements. The reaction rates of the proton and deuteron transfer from $\mathrm{H}_{3}^{+}$(and deuterated isotopologues) to $\mathrm{RH}_{2}$ (and deuterated isotopologues) have not been studied yet. Also the collisional rates for $\mathrm{H}_{2} \mathrm{CCC}$ with $\mathrm{H}_{2}$ are not yet available. The recombination of the linear and cyclic $\mathrm{C}_{3} \mathrm{H}_{3}^{+}$with electrons has been studied by McLain et al. (2005) and Adams \& Babcock (2005), but it cannot be confirmed that the skeleton of the ion is kept during the reaction. The deuteration of the $\mathrm{C}_{3} \mathrm{H}_{2}$ isomers will be better understood if the ionic intermediates, $\mathrm{C}_{3} \mathrm{H}_{3}^{+}, \mathrm{C}_{3} \mathrm{H}_{2} \mathrm{D}^{+}, \mathrm{C}_{3} \mathrm{HD}_{2}^{+}$, and $\mathrm{C}_{3} \mathrm{D}_{3}^{+}$, were observed in dark clouds. Although laboratory-measured rotational spectra of

\footnotetext{
7 This is indeed the case for low-mass cores in the Taurus complex, where Caselli et al. (2008) report similar column densities of ortho- $\mathrm{H}_{2} \mathrm{D}^{+}$toward 5 prestellar and 2 protostellar cores: $N\left(\mathrm{o}-\mathrm{H}_{2} \mathrm{D}^{+}\right) \sim 1-5 \times 10^{13} \mathrm{~cm}^{-2}$. The electron fractions in the outer regions of typical low-mass cores as inferred from the $\mathrm{DCO}^{+} / \mathrm{HCO}^{+}$and $\mathrm{HCO}^{+} / \mathrm{CO}$ ratios are similar: $\sim 10^{-8}-10^{-6}$ (Caselli 2002, and references therein).
}

these species are unavailable at present, high level quantum calculations for the $\mathrm{C}_{3} \mathrm{H}_{3}^{+}$system are available to guide laboratory searches (Huang \& Lee 2011). With precise laboratory rest frequencies in hand, deep radio astronomical searches for these ions could be undertaken, and the observed column densities (or upper limits) would allow refinements to chemical models of dark clouds.

Now that the rotational spectrum of HDCCC has been measured in the millimetre band and the molecule has been detected in three sources, a comprehensive kinetic model is needed to aid interpretation of the existing astronomical observations and to guide future observations of the $\mathrm{C}_{3} \mathrm{H}_{2}$ system. $\mathrm{H}_{2} \mathrm{CCC}$ and $c-\mathrm{C}_{3} \mathrm{H}_{2}$ are currently considered separately in the KIDA chemical reaction database (Wakelam et al. 2015). However, to our knowledge, no complete model that distinguishes between the possibly different deuteration pathways for these two species currently exists. With the above caveats on missing laboratory data, we are working on a chemical model that includes the deuterated forms and spin states of these species, following the methods laid out in Sipilä et al. (2015). Observationally, several additional transitions should be measured in HDCCC, preferably in the centimetre band, thereby allowing a more accurate determination of the $\mathrm{D} / \mathrm{H}$ ratio in $\mathrm{H}_{2} \mathrm{CCC}$. The $2_{0,2}-1_{0,1}$ transition at $38.77 \mathrm{GHz}$ should be six times more intense, and the two $K_{\mathrm{a}}=1$ transitions at 38.28 and $39.25 \mathrm{GHz}$ should be comparable to the line at $19.38 \mathrm{GHz}$. Unfortunately, it might not be feasible to observe the singly deuterated HDCCC in the less dense regions listed in Table 7, because the lines of $\mathrm{H}_{2} \mathrm{CCC}$ are not very intense there. However, there are a number of cold dark clouds, prestellar cores, and protostellar cores in which HDCCC might be detectable, if the $\mathrm{D} / \mathrm{H}$ ratio and the $c-\mathrm{C}_{3} \mathrm{H}_{2} / \mathrm{H}_{2} \mathrm{CCC}$ isomeric ratio are comparable to those in TMC-1, TMC-1C, and L1544. These include L1527, Lupus-1, Lupus1-A, L483, ChaMMS1, and others where $\mathrm{H}_{2} \mathrm{CCC}$ has been detected (Sakai et al. 2009b, a; Cordiner et al. 2012). Extending the determination of the $\mathrm{D} / \mathrm{H}$ ratio in both isomers might serve as an independent test of models of dark cloud chemistry.

Acknowledgements. This work is carried out within the Collaborative Research Centre 956, sub-project [B2], funded by the Deutsche Forschungsgemeinschaft (DFG), and has also been supported by the NASA grant NNX13AE59G. S. Spezzano wishes to thank the Bonn Cologne Graduate School of Physics and Astronomy (BCGS) for financial support. Any opinions, findings, and conclusions in this article are those of the authors and do not necessarily reflect the views of the National Science Foundation.

\section{References}

Adams, N. G., \& Babcock, L. M. 2005, J. Phys. Conf. Ser., 4, 38 Bell, M. B., Avery, L. W., Matthews, H. E., et al. 1988, ApJ, 326, 924 
Brünken, S., Gupta, H., Gottlieb, C. A., McCarthy, M. C., \& Thaddeus, P. 2007, ApJ, 664, L43

Cernicharo, J., Guélin, M., Menten, K. M., \& Walmsley, C. M. 1987, A\&A, 181, L1

Cernicharo, J., Gottlieb, C. A., Guélin, M., et al. 1991, ApJ, 368, L39

Cernicharo, J., Cox, P., Fossé, D., \& Güsten, R. 1999, A\&A, 351, 341

Caselli, P. 2002, Planet. Space Sci., 50, 1133

Caselli, P., \& Ceccarelli, C. 2012, A\&ARv, 20, 56

Caselli, P., Vastel, C., Ceccarelli, C., van der Tak, F. F. S., \& Bacmann, A. 2008, A\&A, 492, 703

Chabot, M., Béroff, K., Gratier, P., Jallat, A., \& Wakelam, V. 2013, ApJ, 771, 90

Cordiner, M., Charnley, S. B., Wirström, E. S., \& Smith, R. G. 2012, ApJ, 744, 131

Cuadrado, S., Goicoechea, J. R., Pilleri, P., et al. 2015, A\&A, 575, A82

Emprechtinger, M., Caselli, P., Volgenau, N. H., Stutzki, J., \& Wiedner, M. C. 2009, A\&A, 493, 89

Fossé, D., Cernicharo, J., Gerin, M., \& Cox, P. 2001, ApJ, 552, 168

Gauss, J., \& Stanton, J. F. 1999, J. Mol. Str., 485, 93

Gerin, M., Wootten, H. A., Combes, F., et al. 1987, A\&A, 173, L1

Goldsmith, P. F., \& Langer, W. D. 1999, ApJ, 517, 209

Gottlieb, C. A., Killian, T. C., Thaddeus, P., et al. 1993, J. Chem. Phys., 98, 4478

Huang, X., \& Lee, T. J. 2011, ApJ, 736, 33

Kawaguchi, K., Kaifu, N., Ohishi, M., et al. 1991,PASJ, 43, 607

Kim, E., \& Yamamoto, S. 2005, J. Mol. Spectr., 233, 93

Liszt, H., Sonnentrucker, P., Cordiner, M., \& Gerin, M. 2012, ApJ, 753, L2

McLain, J. L., Poterya, V., Molek, C. D., et al. 2005, J. Phys. Chem. A, 109, 5119

Müller, H. S. P., Schlöder, F., Stutzki, J., \& Winnewisser, G. 2005, J. Mol. Struct., 742,215
Park, I. H., Wakelam, V., \& Herbst, E. 2006, A\&A, 449, 631 Pety, J., Teyssier, D., Fossé, D., et al. 2005, A\&A, 435, 885

Pety, J., Gratier, P., Guzmán, V., et al. 2012, A\&A, 548, A68

Sakai, N., \& Yamamoto, S. 2013, Chem. Rev., 113, 8981

Sakai, N., Sakai, T., Hirota, T., Burton, M., \& Yamamoto, S. 2009a, ApJ, 697, 769

Sakai, N., Sakai, T., Hirota, T., \& Yamamoto, S. 2009b, ApJ, 702, 1025

Schöier, F. L., van der Tak, F. F. S., van Dishoeck, E. F., \& Black, J. H. 2005, A\&A, 432, 639

Sipilä, O., Caselli, P., \& Harju, J. 2015, A\&A, 578, A55

Spezzano, S., Tamassia, F., Thorwirth, S., et al. 2012, ApJS, 200, 1

Spezzano, S., Brünken, S., et al. 2013, ApJ, 769, L19

Talbi, D., \& Herbst, E. 2001, A\&A, 376, 663

Talbi, D., Hickman, A. P., Kashinski, D., Malenda, R. F., \& Redondo, P. 2009, J. Phys. Conf. Ser., 192, 012014

Teyssier, D., Hily-Blant, P., Gerin, M., et al. 2005, ESA SP, 577, 423

Thaddeus, P., Gottlieb, C. A., Gupta, H., et al. 2008, ApJ, 677, 1132

Tokudome, T., Sakai, N., Sakai, T., Takano, S., \& Yamamoto, S. 2013, ASP Conf. Ser., 476, 355

Troscompt, N., Faure, A., Maret, S., et al. 2009, A\&A, 506, 1243

Turner, B. E. 2001, ApJS, 136, 579

Turner, B. E., Herbst, E., \& Terzieva, R. 2000, ApJS, 126, 427

van der Tak, F. F. S., Black, J. H., Schöier, F. L., Jansen, D. J. M., \& van Dishoeck, E. F. 2007, A\&A, 468, 627

Vrtilek, J. M., Gottlieb, C. A., Gottlieb, E. W., Killian, T. C., \& Thaddeus, P. 1990, ApJ, 364, L53

Wakelam, V., Loison, J.-C., Herbst, E., et al. 2015, ApJS, 217, 20

Ward-Thompson, D., Motte, F., \& Andre, P. 1999, MNRAS, 305, 143

Wiesenfeld, L., \& Faure, A. 2013, MNRAS, 432, 2573

Wu, Q., Hao, Q., Wilke, J. J., et al. 2010, J. Chem. Theory Comput., 6, 3122 